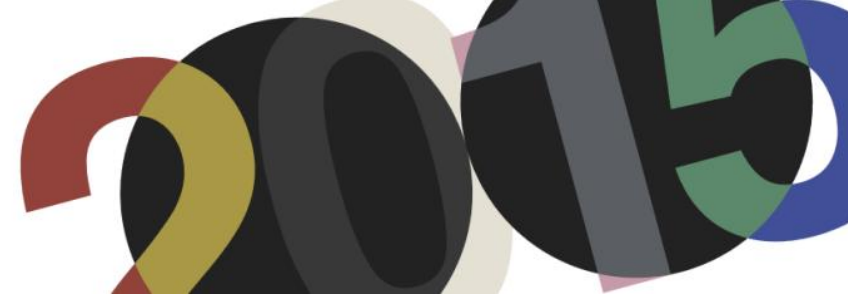

DOI: http://dx.doi.org/10.4995/LC2015.2015.783

\title{
Le Corbusier y Lúcio Costa. Diálogos sobre la síntesis de las artes
}

\section{F. Fernandes da Silva}

Faculdade de Arquitetura e Urbanismo. Universidade de São Paulo

\begin{abstract}
Resumen: En la poética de Le Corbusier, el arte comparece como presencia continua y articulada propuesta en los diálogos entre pintura, escultura y arquitectura, procedimiento que confluye posteriormente en la noción de síntesis de las artes. Es en ese aspecto de su producción que nos detenemos en este trabajo con los textos del arquitecto que se refieren al tema y analizando la interlocución que establece con el teórico brasileño Lúcio Costa. Damos relieve a dos momentos importantes del análisis del tema de los dos arquitectos: primero durante la segunda visita de Le Corbusier a Brasil en 1936, cuando presenta La Arquitectura y las Bellas Artes, texto en el que incorpora a sus ya conocidos postulados arquitectónicos la noción de síntesis de las artes, considerada como forma de ofrecer a la arquitectura recursos expresivos que van más allá del lenguaje abstracto y técnico del funcionalismo. La segunda ocasión de diálogo entre Le Corbusier y Lúcio Costa tiene lugar durante el Congreso Internacional de Artistas, organizado por la UNESCO en Venecia, cuando desenvuelven consideraciones sobre la relación entre arte y arquitectura.
\end{abstract}

Abstract: In the poetics of Le Corbusier, art appears as a continuous and articulate presence, as proposed in the dialogs between painting, sculpture and architecture, a process that converges, later, in the notion of the synthesis of the arts. It is on this aspect of his work that we focus exploring texts written by the architect on the theme. The proposed collaboration between the major arts-architecture, painting and sculpting - is recorded in a paper that the architect presented during his second visit to Brazil, in 1936, when he met Lúcio Costa, the Brazilian architect and theoretician, who was attuned to the poetics of Le Corbusier concerning the relationship between architecture and visual arts. The paper by Le Corbusier A Arquitetura e as Belas Artes [Architecture and Fine Arts], from 1936, emphasizes the idea of modern architecture in dialogue with the machine age, and to this well-known formula, a new topic is added: the collaboration between architecture and the major arts of painting and sculpting. In this way, Le Corbusier in 1952, participates in the International Conference of Artists, organized by Unesco in Venice, this conference was another opportunity for dialog between Lúcio Costa and Le Corbusier, emphasizing the poetic dimension of the architecture.

Palabras clave: síntesis de las artes; Le Corbusier; Lúcio Costa; arquitectura moderna. Keywords: synthesis of the arts; Le Corbusier; Lúcio Costa; modern architecture.

\section{Introducción}

En la poética de Le Corbusier, el arte comparece como presencia continua y articulada propuesta en los diálogos entre pintura, escultura y arquitectura, procedimiento que confluye posteriormente en la noción de síntesis de las artes. Es en ese aspecto de su producción que nos detenemos en este trabajo empleando los textos del arquitecto que se refieren al tema y estableciendo relaciones con sus obras arquitectónicas. En este contexto le conferimos un énfasis especial a los momentos del encuentro entre Le Corbusier y Lúcio Costa, cuando abordan el tema de la síntesis de las artes en un diálogo fructífero con significativos desdoblamientos en la arquitectura moderna brasileña.

La propuesta de colaboración entre las artes mayores -arquitectura, pintura y escultura- está registrada en el texto que el arquitecto presenta durante su segunda visita a Brasil, en 1936, cuando entra en contacto con Lúcio Costa, arquitecto y teórico brasileño, afinado con la poética corbusiana en los aspectos relacionados al diálogo entre arquitectura y artes visuales. En este encuentro surge la concepción del primer ejemplar significativo de la 
arquitectura moderna en Brasil - el Ministerio de Educación y Salud de Rio de Janeiro. El mismo se convierte en paradigma de la arquitectura realizada posteriormente en el país, en la que el tema de la síntesis de las artes será una constante, caracterizada por el trabajo conjunto de arquitectos, pintores, escultores que tienen como mentor a Le Corbusier, el cual encuentra en Lúcio Costa a su principal interlocutor.

El texto que Le Corbusier le confia a Lúcio Costa en 1936, fue publicado casi medio siglo después por el arquitecto brasileño en la Revista do Patrimônio Histórico e Artístico Nacional con el título Le Corbusier: L' Architecture et les Arts Majeurs ${ }^{1}$. Este texto es importante puesto que en él Le Corbusier incorpora la idea de síntesis de las artes, que según el autor, puede ofrecer a la arquitectura recursos expresivos que van más allá del lenguaje abstracto y técnico del funcionalismo.

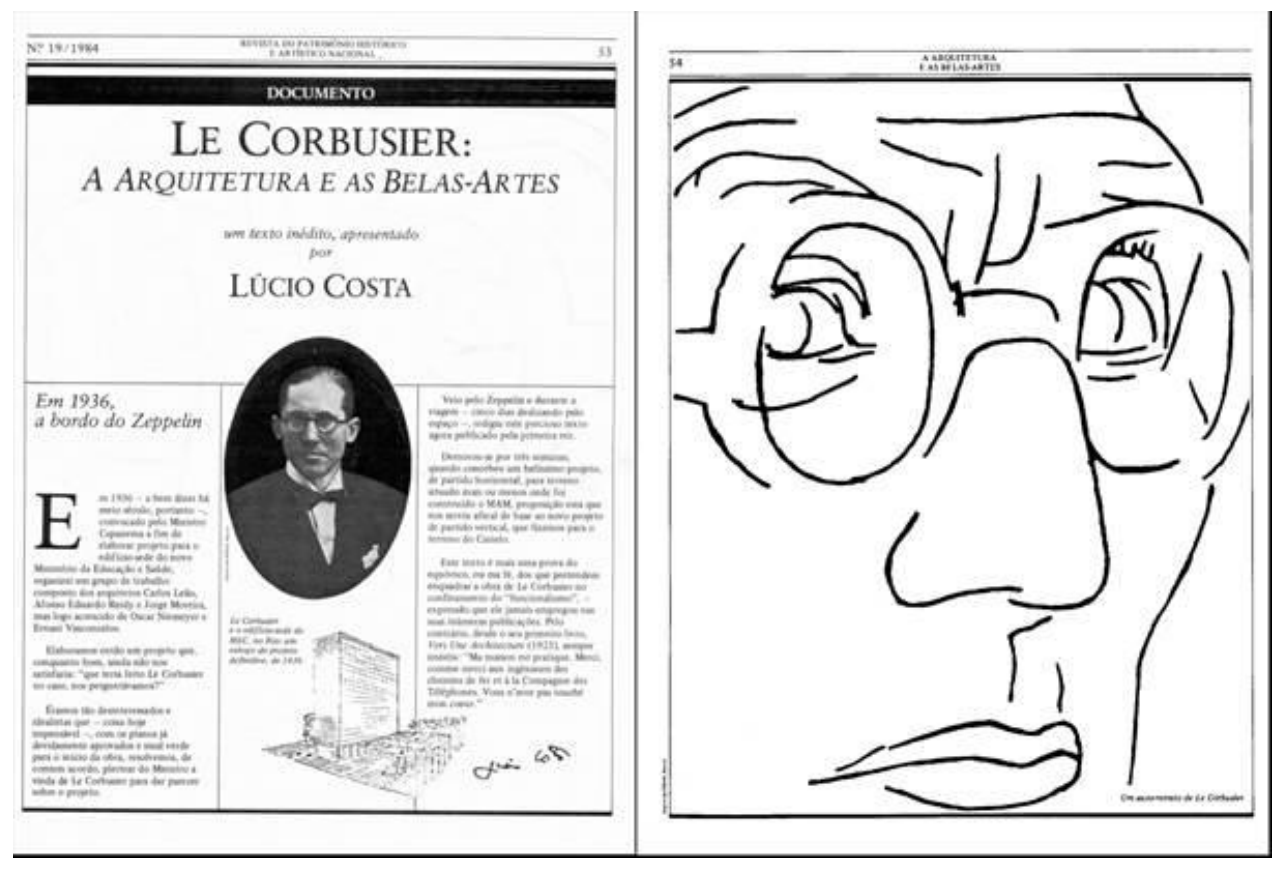

1. Le Corbusier: L’Architecture et les Arts Majeurs (1936), Revista IPHAN, presentación L.Costa.

En octubre del mismo año Le Corbusier participa en Roma del congreso Rapporti dell' architettura con le arti figurative, promovido por la Fondazione Volta. En la ocasión presenta el texto "Les tendances de l'architecture rationaliste en rapport avec la collaboration de la peinture et de la sculture ${ }^{2}$." Se trata del mismo texto que Le Corbusier le confía a Lúcio Costa durante su estancia en Brasil y que recién en 1980 fue publicado en este país. Es interesante observar que el subtítulo de la publicación brasileña corresponde al título del texto presentado en el congreso italiano y publicado en los Anales do congreso como esclarece Rosa Tamburini, responsable de la organización de los escritos de Le Corbusier en lengua italiana.

\footnotetext{
${ }^{1}$ Le Corbusier: A Arquitetura e as Belas-Artes ( L'Architecture et les Arts Majeurs). In Revista do Patrimônio Histórico e Artístico Nacional n.19, 1984, p.53-68.

${ }^{2}$ Le tendenze dell'architettura razionalista in rapporto alla collaborazione della pittura e della scultura. In Le Corbusier Scritti, org. Rosa Tamburini. Torino: Einaudi Editori, 2003, pp.281-294. De acuerdo com la organizadora de la obra el texto fue originalmente publicado in Reale Accademia d'Italia, Fondazione Alessandro Volta, Convegno di Arti, Rapporto dell'architettura con le arti figurative, Atti del VI Convegno, Roma 25-31 ottobre1936, Roma 1937, pp. 16-26. Hay también una publicación parcial del texto en la Revista Domus 107, novembro 1936, pp.36-38.
} 
La publicación en los Anales del Congreso romano fue ampliamente utilizada por los estudiosos del tema y considerada por Stanislaus von Moos como uno de los primeros textos en que Le Corbusier se dedica al studio de la relacion entre las artes mayores ${ }^{3}$. También Joan Ockam hace referencias a este texto, destacando la idea de colaboración entre las artes propuesta por Le Corbusier y también la importancia que el arquitecto le confiere al uso de colores en la arquitectura, aspecto ya explorado por el pintor Fernand Leger en algunos textos. La historiadora norteamericana revela el trabajo conjunto entre Le Corbusier y Leger en los temas relativos al acercamiento entre arquitectura y artes plásticas y traza un panorama de los debates que tienen lugar en Francia en la segunda posguerra en relación a la síntesis de las artes ${ }^{4}$. Es a partir del traslado de Leger a New York durante la segunda guerra, que Ockman establece la continuidad de la reflexión sobre la síntesis de las artes en territorio americano. De hecho, la propuesta se retoma en el manifiesto Nueve Puntos sobre la Monumentalidad, elaborado en colaboración por F. Leger, por el historiador suizo S. Giedion y por el arquitecto español J.L. Sert, en el que la síntesis de las artes comparece como elemento de representación cívica, calificando los espacios públicos de la ciudad.

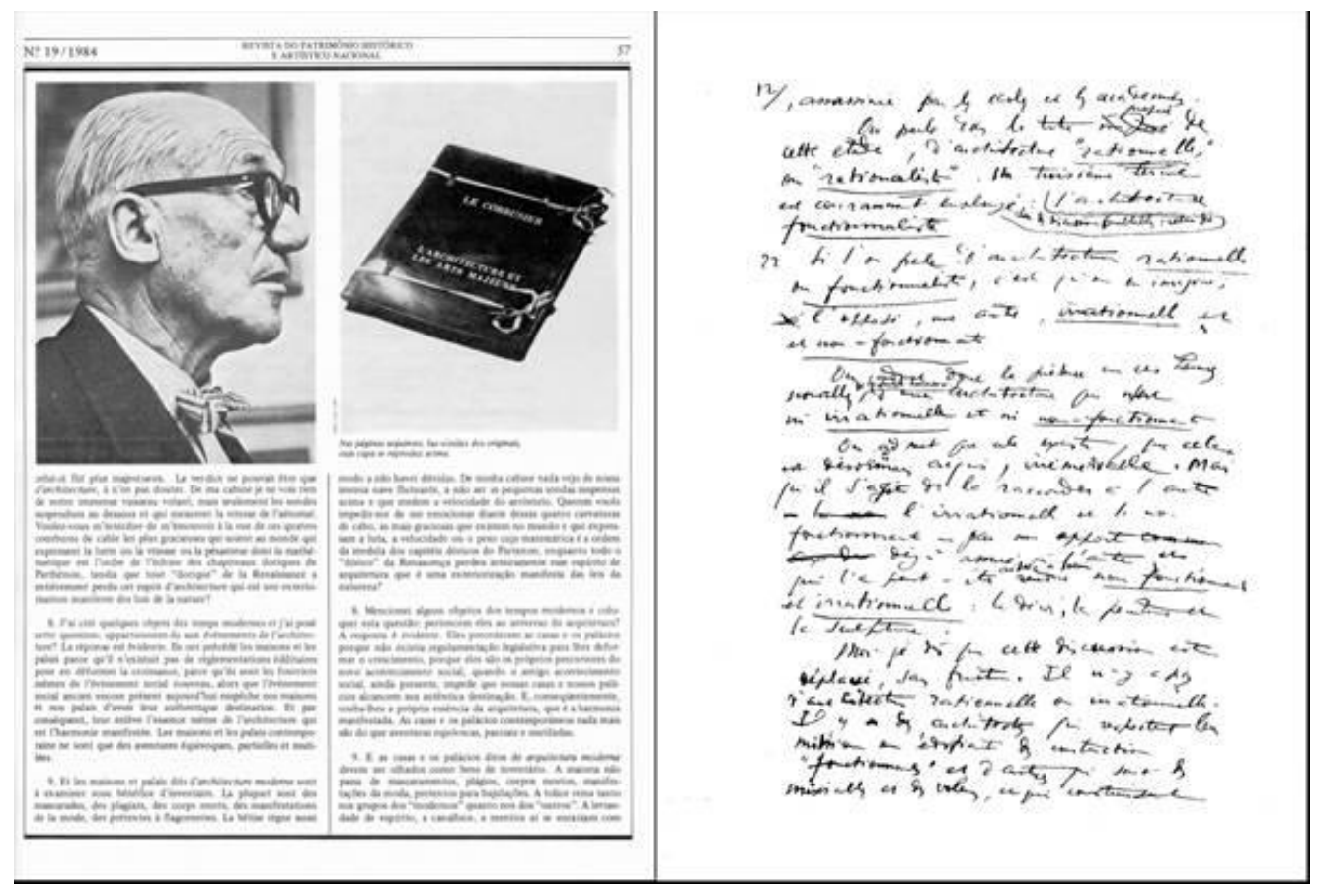

2. Le Corbusier: L'Architecture et les Arts Majeurs (1936). Revista do IPHAN, manuscrito de Le Corbusier.

Como bien observa Juan Calatrava esta nueva historiografía de la arquitectura contemporánea promueve una revisión de la imagen conferida a Le Corbusier como arquitecto funcionalista que aboga por una civilización maquinista. Esta lectura reduccionista queda relativizada en función de nuevos enfoques surgidos en los últimos años, que permiten una visión más compleja y consistente de su obra, que abarca arquitectura, pintura y escultura estableciendo tránsitos y articulaciones entre las distintas esferas expresivas de su producción. En las palabras

\footnotetext{
${ }^{3}$ Stanislaus von Moos. Exhibition Architect? Otra mirada sobre la "síntesis" de Le Corbusier. In Juan Calatrava org. Doblando el Ángulo Recto. Siete ensayos em torno a Le Corbusier. Madrid: Circulo de Bellas Artes, 2009, pp.61-62.

${ }^{4}$ Juan Ockman A Plastic Epic: The Synthesis of the Arts Discourse in France in the Mid-Twentieth Century. In Eeva-Lisa Pelkonen and Esa Laaksonen, ed. Architecture + Art.New Visions, New Strategies. Helsinki: Alvar Aalto Academy, 2007, pp.30-61.
} 
del historiador y crítico español es posible así distinguir "un autre Le Corbusier" a partir de la idea de síntesis de las artes.

En la estela de estas revisiones es importante lanzar una nueva mirada sobre la arquitectura moderna brasileña deudora de primera hora de la propuesta corbusiana de síntesis de las artes y que en las palabras de S. Giedion se presenta como alternativa a la arquitectura racionalista del entreguerra europeo ${ }^{6}$.

\section{Lúcio Costa y Le Corbusier: interlocuciones con la arquitectura moderna brasileña}

El momento definitorio del diálogo entre Le Corbusier y Lúcio Costa aquí citado tiene lugar en Rio de Janeiro en 1936, cuando Le Corbusier visita Brasil por segunda vez y permanece tres semanas impartiendo conferencias y trabajando como consultor del proyecto del Ministerio de Educación y Salud, proyecto realizado por un equipo de arquitectos liderados por Lúcio Costa ${ }^{7}$. Este encuentro propicia la confluencia de ideas y de experiencias que contribuyen a la concepción del primer ejemplar significativo de la arquitectura moderna realizada en Brasil, caracterizada por el trabajo conjunto de arquitectos, pintores, escultores y por el paisajismo de Burle Marx.

Anteriormente Lúcio Costa ya se había manifestado sobre la relación entre arte y arquitectura en su texto de 1934, Razões da Nova Arquitetura (Razones de la Nueva Arquitectura), señalando la importancia del diálogo entre las artes para una producción arquitectónica significativa y de acuerdo con la época moderna ${ }^{8}$. Del mismo período es el texto de Le Corbusier: L'Architecture et Les Arts Majeurs ${ }^{9}$, 1936, en el que el autor enfatiza la concepción de una arquitectura moderna en diálogo con la era de la máquina y por ende pautada por la economía de medios, pero considera que también es acrecentada de valores de espacio, luz y volumen, cualidades arquitectónicas que van más allá de la pura funcionalidad. A esta formulación, ya divulgada en su libro de 1923 Vers une Architecture, añade un nuevo tema, fruto de sus reflexiones más recientes, que se refiere a la colaboración entre la arquitectura y las artes mayores, la pintura y la escultura, considerándola como factor positivo que merece ser utilizado en casos excepcionales. Además, identifica en la policromía la expresión espontánea de la vida y factor esencial de la manifestación arquitectónica.

De esta manera Le Corbusier incorpora a sus postulados la noción de síntesis de las artes, que tendrá desdoblamientos en las reflexiones del arquitecto en la segunda posguerra y también en el ámbito de los Congresos Internacionales de Arquitectura Moderna (CIAM). Estas concepciones tendrán repercusiones en el proyecto del ministerio, concebido en el momento de la definición de esta propuesta. En este se concreta una arquitectura orientada por las directrices de Le Corbusier, que resulta en la elevación de los volúmenes sobre pilotis, en las terrazas-jardín del ático, en las superficies trabajadas con brise-soleil, en los paños de vidrio y en la planta libre del bloque de la administración. A esta significativa adhesión a los postulados modernos de matriz

\footnotetext{
5 Juan Calatrava. Un autre Le Corbusier: l'idée de la synthèse des arts majeurs. In La lettre du Collège de France. Paris: Collège de France, abril 2010, no. 28, pp.18-28. Consultado en la version grabada hospedada en internet en: http://lettre-cdf.revues.org/1049.

${ }^{6}$ S. Giedion O Brasil e a Arquitetura Contemporânea (Zuric, 1956). In Henrique E. Mindlin Arquitetura Moderna no Brasil. Rio de Janeiro: Aeroplano, 1999. (prefácio)

${ }^{7}$ Forman parte del equipo, dirigido por Lúcio Costa, los arquitectos Affonso Eduardo Reidy, Carlos Leão, Oscar Niemeyer, Jorge Moreira y Hernani Vasconcellos.

${ }^{8}$ Lúcio Costa Razões da Nova Arquitetura (1934), in Lúcio Costa. Registro de uma Vivência . São Paulo: Empresa das Artes, 1995, p.108-16.

${ }^{9}$ Le Corbusier: A Arquitetura e as Belas-Artes (L’Architecture et les Arts Majeurs). Revista do Patrimônio Histórico e Artístico Nacional n.19, 1984, p.53-68. ( publicado en portugués et francés).
} 
corbusiana se incorporan trabajos de artistas plásticos, como las esculturas de Bruno Giorgi, Celso Antonio y Jacques Lipschitz, los murales de Cândido Portinari, además de los jardines del pintor y paisajista Roberto Burle Marx.

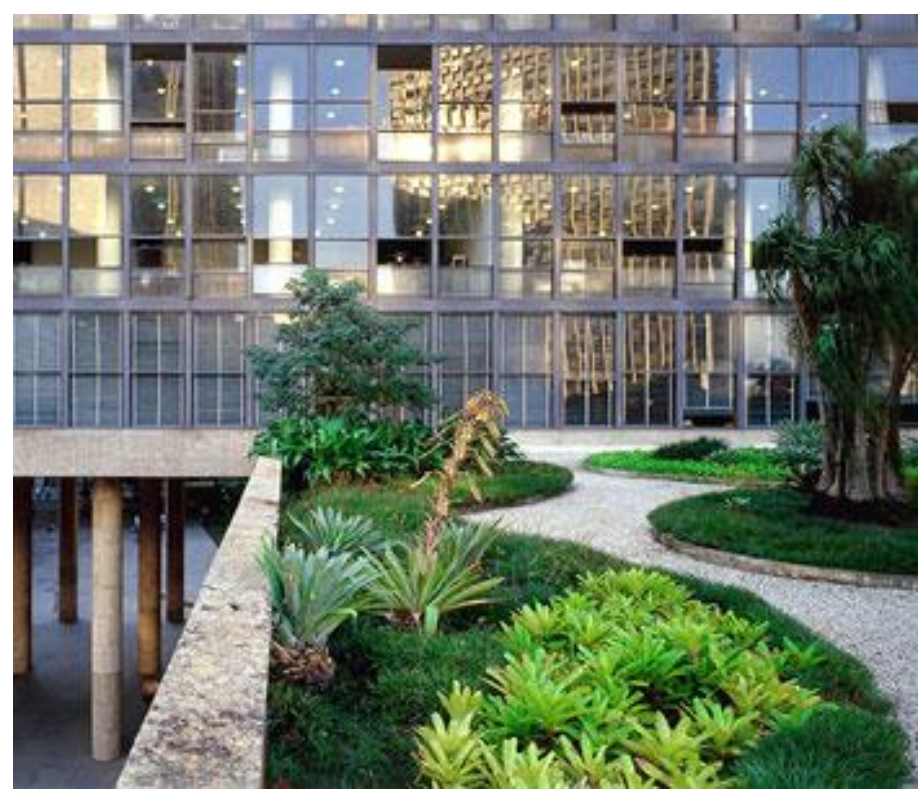

3. Ministerio de Educación y Salud, jardines del paisajista Roberto Burle Marx.

Portinari realiza el dibujo de los azulejos que revisten las superficies de los volúmenes que en la planta baja del edificio conviven con los pilotis. Los azulejos se inspiran en motivos marinos: peces, conchas y caballitos marinos distribuidos en una disposición geométrica que equilibra los elementos figurativos en la concepción del conjunto realizado en blanco y azul, que evocan tanto la ubicación del edificio en una ciudad costera como también la azulejería de los atrios de conventos de la arquitectura tradicional brasileña ${ }^{10}$. Burle Marx concibe los jardines valiéndose de nuevas soluciones formales materializadas en las diversas texturas de la vegetación tropical. Con estas contribuciones la solución arquitectónica de lenguaje moderno aparece mezclada con sugestivas evocaciones locales y se hace matriz de una arquitectura moderna en diálogo con la tradición y con las demás artes.

En un texto de 1987, Carlos Eduardo Comas observa que la posición destacada del edificio en relación al espacio urbano es uno de los aspectos que le confieren dimensión de monumentalidad, convirtiéndose en un marco de referencia y ganando así atributos que lo califican en tanto elemento de rememoración ${ }^{11}$. El autor observa que esos valores están distantes de las propuestas modernas que buscaban en el prototipo la posibilidad de reproducir en serie el edificio o sus partes en producción industrial. Por lo tanto, como señalaba Comas, en principio, las concepciones de monumento y prototipo no dialogan y aparecen como aparente contradicción en el interior de la obra. En este sentido cabe advertir que durante la segunda guerra mundial, cuando se construye el edificio,

\footnotetext{
${ }^{10}$ Los azulejos, por solicitud del propio Portinari fueron realizados en el Atelier de Azulejos Ozirarte, pequeña industria creada y dirigida en la década de 1940 por Paulo Rossi Ozir, volcada a la producción de azulejos artísticos. Rossi Ozir declara que fue realizado un largo proceso de experimentación con los colores hasta alcanzar un tono de azul semejante al utilizado en los azulejos portugueses de la época colonial. Sobre Paulo Rossi Ozir véase Paulo Mendes de Almeida, De Anita ao Museu. São Paulo: Editora Perspectiva, 1976, p.161-13.

${ }^{11}$ Carlos Eduardo Comas, Protótipo e Monumento, um ministerio, o ministerio . En Textos Fundamentais sobre história da arquitetura moderna: vol1, organización Abílio Guerra. São Paulo: Romano Guerra, 2010, p.63-77. (publicado inicialmente in revista Projeto 102, ago 1987, p.136-49)
} 
vamos a presenciar la entrada de la noción de monumento en las discusiones del campo arquitectónico internacional. Analizar este cambio de posición nos ayuda a comprender los distintos factores que confluyen en la propuesta del edificio del Ministerio.

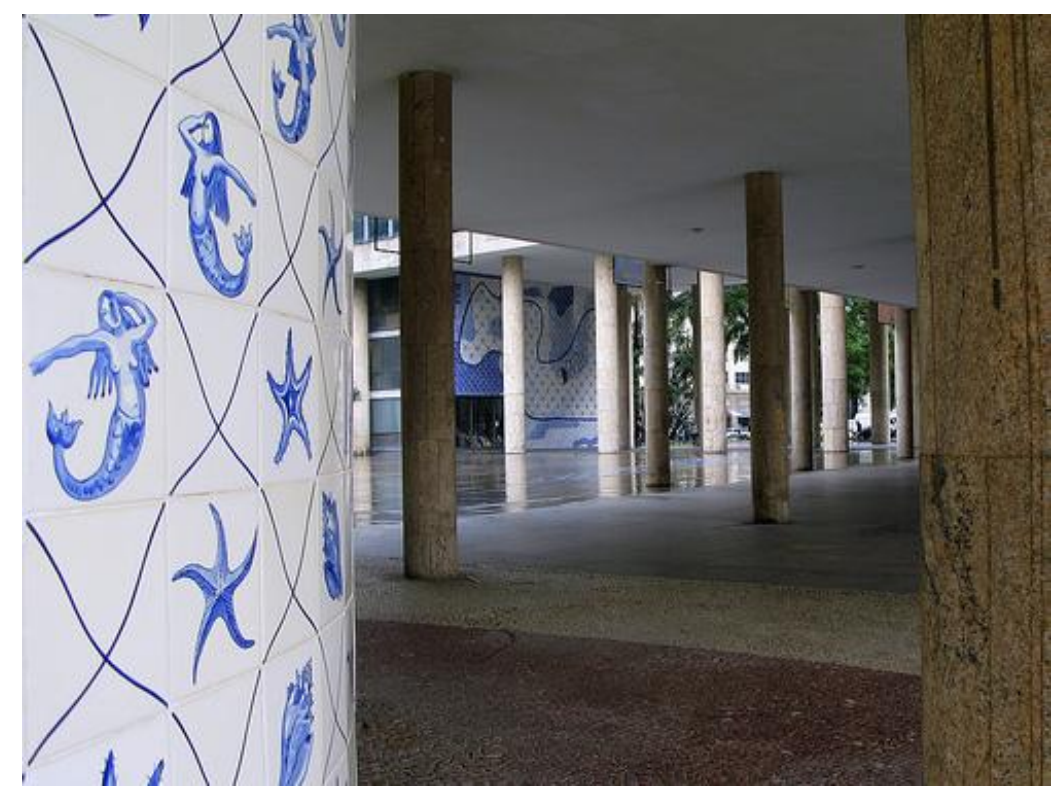

4. Ministerio de Educación y Salud, planta baja - pilots e azulejos.

Le Corbusier ya había introducido el tema de la monumentalidad en clave moderna en su proyecto para la sede de la Sociedad de las Naciones en Ginebra (1927-28) y será por obra de S.Giedion, J.L. Sert y F. Leger, cercanos a Le Corbusier, que se retomará la cuestión como parte del proceso de revisiones de las directrices de la arquitectura moderna durante y después de la segunda guerra mundial. Exiliados en Nueva York, en la diáspora de artistas, arquitectos e intelectuales a América provocada por la II Guerra, Giedion, Sert y Leger, lanzan en 1943 el manifiesto Nueve puntos sobre la Monumentalidad. En el mismo, la noción de monumento se emplea en su concepción etimológica de memoria, de aquello que recuerda, y en tanto memoria, moviliza aspectos subjetivos y emotivos como la pertinencia al lugar y la identidad, cuestiones distantes de una modernidad que hasta entonces se planteaba prioritariamente como propuesta de futuro. Asimismo, el manifiesto sostiene que uno de los elementos que contribuye a la elaboración de una arquitectura-monumento es la participación de otras esferas artísticas, como la pintura y la escultura, en la concepción arquitectural, en la medida en que estas la califican e individualizan.

De este modo, como indica Comas, no es de extrañar que Philip Goodwin en 1943 presente el edificio del Ministerio como solución de una metodología funcionalista pautada por la eficiencia operativa ${ }^{12}$. S.Giedion hará una lectura distinta en su texto Por una Nueva Monumentalidad publicado en la recopilación organizada por Paul Zucker en 1944, en la que se presentan fotos del Ministerio como solución ejemplar de las formulaciones por él defendidas en relación a la monumentalidad. La aparente dicotomía radica en el hecho de que el análisis de Giedion se da en el momento en que el crítico está involucrado con la proposición de monumento que incorpora el aspecto de la relación entre las artes, y así lanza una mirada sobre aspectos de la obra del ministerio que permanecían en un segundo plano frente a los evidentes principios corbusianos allí concretados y sintonizados con la época maquinista. 


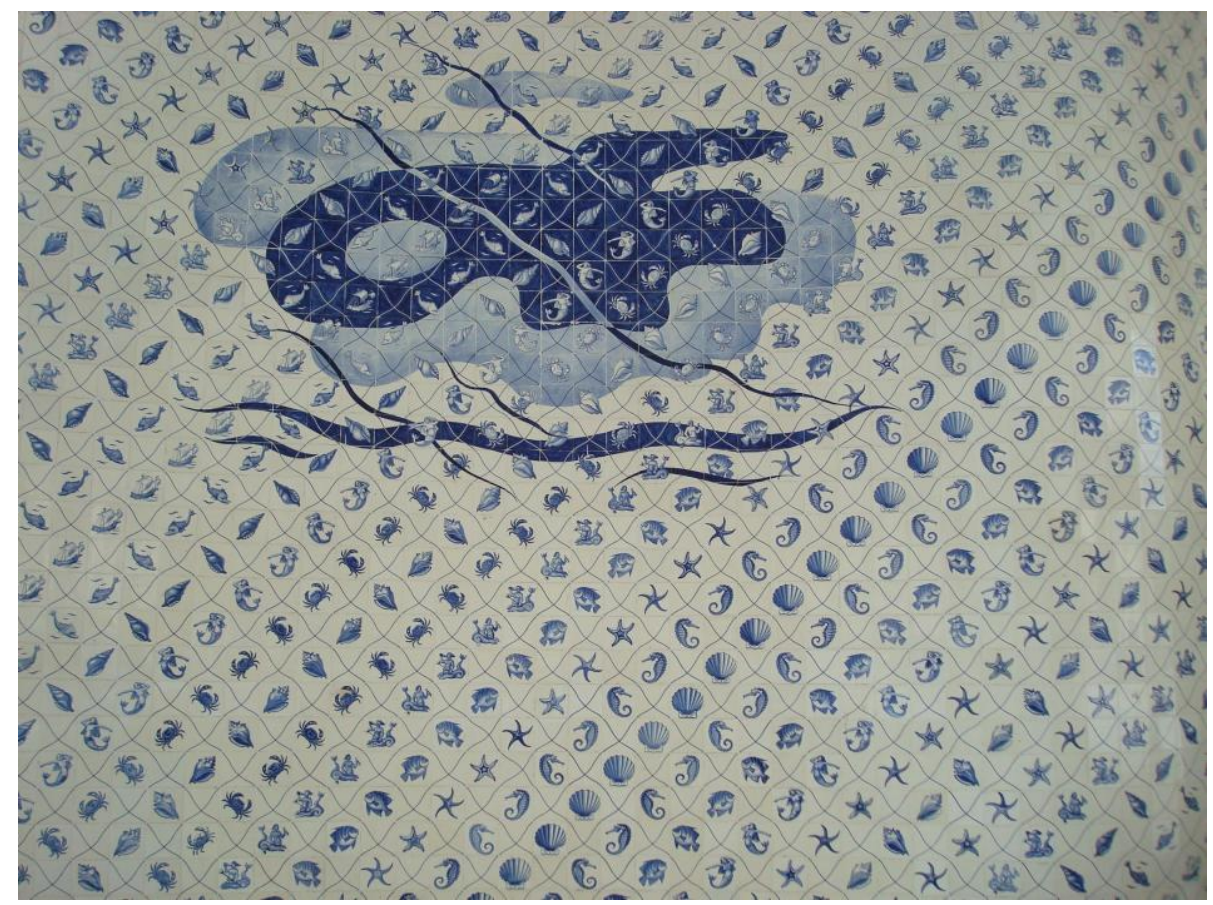

5. Ministerio de Educación y Salud, azulejos en motivos marinos de Candido Portinari

Intencionalmente o no las características de monumento atribuidas al Ministerio condicen con el ambiente cultural que lo produjo, en el que el tema de la brasileñidad gana importancia en la concepción de una arquitectura que se anhelaba expresión del país y representativa de una institución dedicada a la educación y a la cultura. La idea de nación era un factor de cohesión importante en la política del gobierno Vargas, de carácter autoritario y populista. Por otro lado, la presencia de Lúcio Costa como líder del equipo que proyecta el Ministerio reverbera en sus constantes inferencias en lo que atañe a la representatividad del edificio, lo que acrecentaba al proyecto características poco ligadas a la pura racionalidad. Además, tenemos la proximidad de Lúcio Costa con las cuestiones ligadas a la preservación, en las que el término monumento nunca perdió su prestigio en sus aspectos de memoria e identidad.

A partir del proyecto del Ministerio el tema de la síntesis de las artes será una constante en el pensamiento de la arquitectura moderna brasileña. En este contexto se desenvuelven las principales obras del arquitecto brasileño Oscar Niemeyer, desde el proyecto de la Igreja da Pampulha en colaboración con el pintor Cândido Portinari, hasta los palacios de Brasilia. Otros arquitectos como el carioca Afonso Eduardo Reidy, además de otros menos afinados con los principios corbusianos, se alinean a esta tendencia que acaba por caracterizar la arquitectura moderna brasileña. La reflexión sobre el tema de la síntesis de las artes en Brasil ocurre en paralelo a su desarrollo en el campo internacional, y aunque este debate no se desenvuelva de modo constante y articulado, se puede observar que adoptará distintos sentidos a lo largo del tiempo, muchas veces yendo más allá de la especificidad de la interlocución entre arte y arquitectura y definiéndose como propuesta de transformación de la sociedad. 


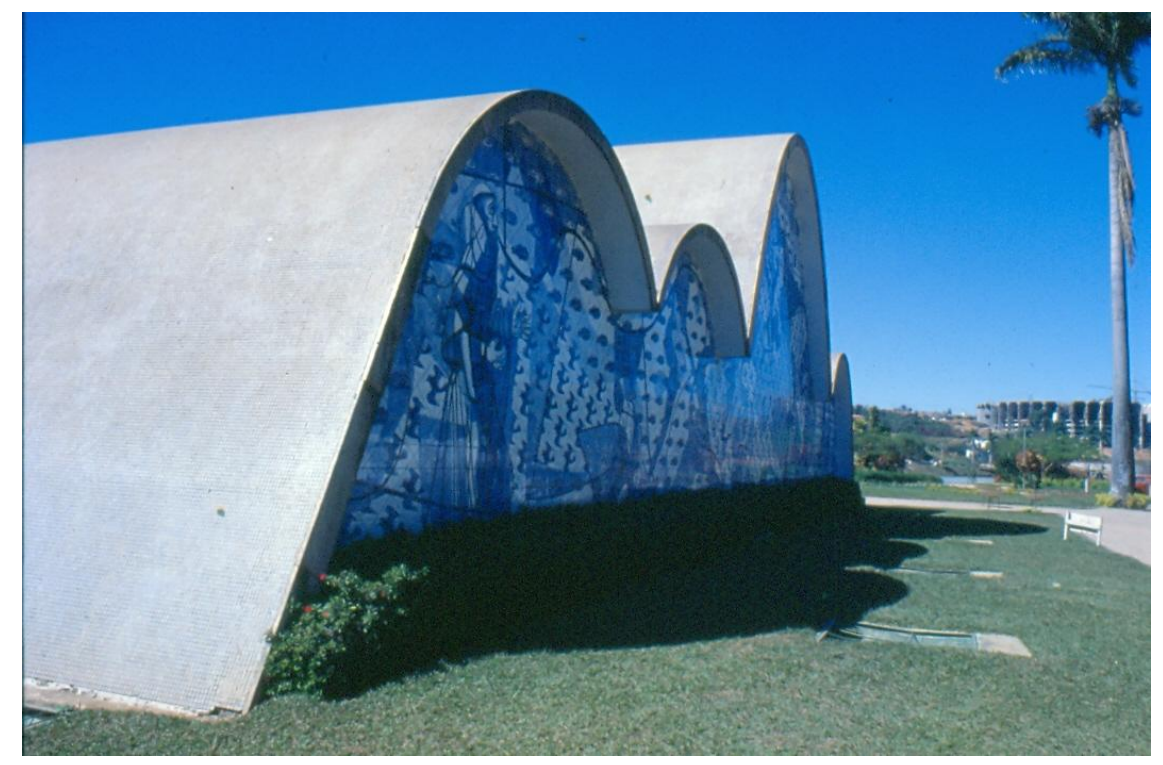

6. Igreja da Pampulha, proyeto Oscar Niemeyer, panel en azulejos Candido Portinari

\section{Le Corbusier y la síntesis de las artes}

Charles- Eduard Jeanneret (Le Corbusier) se establece en París en 1917 donde conoce a Amédée Ozenfant, quien lo vincula a la vanguardia parisiense, en aquel momento volcada a las discusiones sobre el cubismo, y donde tiene la oportunidad de relacionarse con diversos artistas, como Juan Gris, Fernand Leger y Jacques Lipchitz. Al año siguiente, Jeanneret y Ozenfant escriben conjuntamente el manifiesto Aprés le cubisme, que publicado al terminar la primera guerra mundial, se presenta como reflexión estética y social, insertándose en el proceso de reconstrucción en curso en el ambiente cultural francés ${ }^{13}$.

Las elaboraciones formales del purismo propuestas en el manifiesto definen una poética pautada por elementos escogidos entre objetos ya existentes, de los cuales se extraen formas específicas. La elección de estos objetos se define por leyes mecánicas, que establecen que los mismos deben tender hacia un tipo determinado de evolución de las formas, caracterizado por la máxima utilidad y economía de fabricación. Además, también se opta por los más banales, aquellos que se insertan en la vida cotidiana y que mejor representan objetos-tipo, perfectamente legibles y de fácil identificación, con características de generalidad y que tienden a lo estándar.

En 1920 Ozenfant y Le Corbusier fundan con el poeta y publicitario dadaísta Paul Dermée la revista L'Esprit Nouveau, que se torna vehículo de difusión de sus ideas hasta $1925^{14}$. En ella se presentan temas que remiten a experiencias artísticas precedentes, como el impresionismo y el cubismo, y que señalan la conformación de un lenguaje abstracto y lógico, basado en la búsqueda de elementos constantes de la sensibilidad plástica, que aparece en la conformación de los cilindros, de las esferas y de los cubos, y también en los elementos simples y cotidianos, asumidos como nuevos valores y presentes en botellas, vasos y macetas, considerados como parte de la búsqueda de repertorios específicos de la nueva cultura pictórica. ${ }^{15}$

\footnotetext{
${ }^{13}$ Ozenfant e Jeanneret (Le Corbusier) Depois do cubismo (Aprés le Cubisme). Introdução Carlos Alberto Ferreira Martins. São Paulo: Cosac Naify, 2005.

${ }^{14}$ Es en este momento -1925- cuando Charles-Edouard Jeanneret adoptará el pseudónimo Le Corbuisier.

${ }^{15}$ Roberto Gabetti e Carlo Olmo, Le Corbusier e L’Esprit Nouveau. Torino: Einaudi Editori, 1975, p.27.
} 
El acercamiento de Le Corbuisier a Fernand Leger, que en ese momento se dedicaba a la reflexión sobre la pintura y la arquitectura, refuerza su interés por el tema. El trabajo conjunto de ambos se concreta en el Pabellón L'Esprit Nouveau, realizado para la Exposición de Artes Decorativas de París, en 1925. La obra sintetiza los estudios conducidos hasta entonces por el arquitecto en relación a la vivienda. En ella se presenta una célula immeuble-villas derivada de la Casa Citrohan, que a su vez evoca el automóvil en tanto máquina que se basa en la eficiencia y en la simplicidad, características que, según el arquitecto deberían ser parte de la casa moderna. El razonamiento desarrollado por Le Corbuisier, que conducía del módulo hasta la esfera urbana, también está presente en la propuesta del pabellón. Al lado de la célula de vivienda, el arquitecto introduce un ambiente que alberga un diorama donde los proyectos de la Ville Contemporaine y del Plan Voisin se presentan como ejemplos de los posibles desdoblamientos del empleo del prototipo a escala urbana. La espacialidad del pabellón también dialoga con las demás artes, en interacción con la escultura de Lipchitz y la pintura de Leger, además de albergar la propia obra pictórica de Le Corbusier ${ }^{16}$.

La progresión de la obra arquitectónica de Le Corbusier revela su paulatina adhesión a la síntesis de las artes. Su actividad como pintor funciona como campo experimental para la concepción espacial de la arquitectura y en ella se inserta a través de paneles y elementos esculturales, haciendo unitaria la doble acción arquitectónica y plástica. Su trayectoria se centra en la concepción de una arquitectura en sintonía con la sociedad moderna y se desdobla en pinturas, dibujos, collages, murales y tapices. El arquitecto considera estos últimos, por su potencial movilidad, el mural moderno (Muralnomad), que acompaña al hombre urbano cuando cambia de casa. En la poética de Le Corbusier, la emoción plástica y la emoción arquitectural son constantes que remiten a una obra que resuena en diapasón, en sintonía con las leyes, las relaciones y la proporción. En ese universo, es factible invitar a pintores y escultores a alinearse con la arquitectura.

La reflexión sobre la síntesis de las artes también aparece en los sucesivos textos del arquitecto que al mismo tiempo que esclarecen los principios guía de la moderna arquitectura ligada a la civilización de la máquina, eligen la síntesis de las artes mayores como calificadora de esa misma arquitectura. Le Corbusier retoma la problemática de la relación entre las artes en su texto "L'espace indicible"17 Aquí el espacio es considerado como realización de la emoción plástica evocada en la consonancia de tres artes: la pintura, la escultura y la arquitectura. En relación a la síntesis, considera que la aproximación entre esas artes se hace en función del espacio, elemento común a todas ellas. Con todo, las espacialidades se generan a partir de los medios propios de cada una de las artes y confluyen para promover la emoción estética, vista por el autor como esencialmente una función espacial. Así, la acción de la obra se extiende al ambiente, a las paredes de las salas, a las plazas públicas y al paisaje.

Por lo tanto, se verifica una ampliación de la inserción de las artes, ahora consideradas en el ambiente urbano, a semejanza de lo que había sido propuesto por Giedion, Sert y Leger en relación a la "nueva monumentalidad", con todo, la idea de síntesis se desplaza hacia la concepción espacial preservando así las especificidades de cada medio de expresión. Formulada por el arquitecto en 1946, esta concepción espacial será explotada en sus obras del período, como la Capilla de Ronchamp y el convento de La Turrete, en los que las elaboraciones de luz y la inserción de pinturas del propio arquitecto alimentan la concepción de nuevas espacialidades arquitectónicas, ahora construidas con concreto bruto, que en su rudeza remite a las dificultades enfrentadas por Francia en el proceso de reconstrucción de posguerra.

\footnotetext{
${ }^{16}$ Jean-Louis Cohen. Le Corbusier. La planète comme chantier. Paris: Les Éditions Textuel, 2005.

${ }^{17}$ Le Corbusier. L'Espace Indicible. In L'Architecture d'aujour'hui, (número fora de série). Paris: Éditions de L'Architecture d'aujour'hui, 1946, pp.9-10.
} 


\section{Lúcio Costa y Le Corbusier: interlocuciones entre arte y arquitectura.}

El año de la visita de Le Corbusier a Brasil, el debate sobre la colaboración entre las artes gana un nuevo impulso en París, con la creación de la asociación Unión para el Arte, iniciativa de André Bloc que, desde los años treinta dirige la revista L'architecture d'Aujourd'hui. El periódico se torna uno de los principales vehículos de difusión de los debates y de la producción de la síntesis de las artes. Producto natural de su actuación en favor de esas ideas, en la década de 1950 André Bloc constituye el Groupe Espace, que llevará a cabo constantes investigaciones pictóricas y esculturales de integración con la arquitectura ${ }^{18}$.

Lúcio Costa también continúa trabajando con el tema de la relación entre las artes y en 1948 participa del simposio organizado por la revista inglesa Architectural Review titulado In Search of a New Monumentality ${ }^{19}$, que se inserta en la discusión iniciada en la posguerra como propuesta de revisión de los postulados modernos. El simposio adopta como punto de partida para la reflexión sobre el tema el presupuesto de que la arquitectura funcionalista es insuficiente para enfrentar los problemas del hombre contemporáneo y propone como alternativa la necesidad de una arquitectura que exprese las aspiraciones colectivas. Para tal se retoman las diversas concepciones de la palabra monumentalidad a lo largo del tiempo, buscando circunscribir la que sea más adecuada a las aspiraciones del presente. En el texto escrito para este seminario Lúcio Costa señala la importancia de las contribuciones de la Bauhaus, de Mies van der Rohe y de F.L.Wright para la arquitectura moderna del siglo XX y entre estas destaca el papel de Le Corbusier por su pensamiento que abarca diversos aspectos de la concepción arquitectónica como la técnica y los aspectos funcionales de la construcción, las cuestiones sociológicas y urbanas, además de la dimensión plástica de la arquitectura y sus relaciones con la pintura y la escultura, conformando una totalidad ${ }^{20}$.

Más de una década después del primer encuentro entre Lúcio Costa y le Corbusier surge una nueva oportunidad de diálogo entre los dos arquitectos en relación al tema de la síntesis de las artes. Esta vez ambos participan del Congreso Internacional de Artistas, organizado por la UNESCO en Venecia en $1952^{21}$. En esta ocasión, Lúcio

\footnotetext{
${ }^{18}$ Joan Ockman hace una cuidadosa lectura de los debates sobre la síntesis de las artes en Francia en su texto A Plastic Epic. The Synthesis of the Arts Discourse in France in the Mid-Twentieth Century. In Eeva-Liisa Pelkonen and Esa Laaksonen, (eds) Architecture + art. New Visions, New Strategies. Helsinki: Alvar Aalto Academy, 2007, pp. 30-61.

${ }^{19}$ Los textos del simposio fueron escritos por arquitectos, urbanistas y críticos de arquitectura invitados y están publicados en la revista Architectural Review, n.621, setiembre, 1948, p.117-128, con una introducción, que establece relaciones y divergencias entre los mismos, señalando los principales enfoques. Además de Lúcio Costa, presentado como director del IPHAN y líder del Movimento Moderno en Brasil, participan del simposio: Gregor Paulsson (University of Uppsala), HenryRussell Hitchcock (Wesleyan University), William Holford (University of London), Siegfried Giedion (University of Zurik), Walter Gropius (Harvard University), Alfred Roth (editor de la revista Werk).

${ }^{20}$ Architectural Review, n.621, setiembre, 1948, p. 127. Un estudio profundo sobre Lúcio Costa y la cuestión de la monumentalidad en sus obras, especialmente en relación a Brasilia se encuentra en: Anna Beatriz Ayroza Galvão. A monumentalidade em Lúcio Costa: projeto de arquitetura e cidade moderna (La monumentalidad en Lúcio Costa: Proyecto de arquitectura y ciudad moderna). Tesis de doctorado. São Paulo: FAUUSP, 2005.

${ }^{21}$ Anales del congreso organizado por la UNESCO: El artista en la sociedad contemporánea. Conferência Internacional de Artistas, Venecia, 22-28 de septiembre de 1952. Londres: UNESCO, julio de 1954. La conferencia tiene carácter multidisciplinario con la participación de representantes de las distintas esferas artísticas y su presidencia recayó en Ildebrando Pizzetti; el tema general, el artista en la sociedade contemporánea, es presentado por Giuseppe Ungaretti. Los demás participantes son: Marc Connelly (teatro); Alessandro Blasetti (cine); Arthur Honegger (música); Taha Hussein (literatura); Lúcio Costa (arquitetura); Henry Moore (escultura); Jacques Villon (pintura). Entre los participantes del congreso se encuentran Le Corbuisier, Fernand Leger y José Luis Sert.
} 
Costa escribe el texto El Arquitecto y la Sociedad Contemporánea, ${ }^{22}$ para la participación en el congreso. En él aborda dos temas, el primero sobre la unidad habitacional y el segundo sobre el arquitecto y su papel en el mundo contemporáneo. En relación a este segundo tema, Lúcio Costa retoma el pensamiento de Le Corbusier relevando que desde el principio, el arquitecto buscó situar la arquitectura más allá de lo meramente utilitario y que también recomienda la inclusión de expresiones tradicionales que preserven la facción particular de cada pueblo o cultura. Observa asimismo que el carácter eminentemente utilitario de la arquitectura moderna es incapaz de expresar algún sentido monumental. En sintonía con estas concepciones inserta el episodio singular de la arquitectura moderna brasileña, particularmente la obra del Ministerio (1936) que, según Costa, pone el énfasis en la calidad plástica y en el concepto lírico “...aquilo porque há de sobreviver no tempo, quando funcionalmente já não for útil” (“...esto es porque ha de sobrevivir en el tiempo, cuando funcionalmente ya no sea útil”). Tenemos aquí a Lúcio Costa como lector de Le Corbusier e impulsor de una arquitectura moderna atenta a la permanencia y a la innovación.

En el Congreso de Venecia, Lúcio Costa presenta oralmente un resumen del trabajo, en el que retoma el tema de la síntesis de las artes, reformulando la cuestión por él considerada como una postura de integración. Considera como factor esencial pensar la arquitectura en su dimensión plástica, observando que el trabajo conjunto de profesionales que actúan en distintas esferas artísticas debería darse mucho más como interrelación que como síntesis, quedando así preservada la dimensión específica de cada hacer artístico ${ }^{23}$.

En el mismo seminario, en su comunicación Les rapports des artistas entre eux: Synthèse des arts plastiques, Le Corbuisier enfatiza el fenómeno poético como factor esencial en la elaboración arquitectónica colocando la pintura y la escultura como elementos que provocan emoción, propone también que su concepción anterior de síntesis de las artes gane amplitud y se expanda para incluir la colaboración entre las artes aunque manteniendo las especificidades de cada una de ellas que, con sus papeles singulares, permiten establecer diálogos entre las diferencias. Esta propuesta viene asociada a la idea de un obrador, que posibilite el intercambio entre las diversas esferas artísticas, en el que las obras se realicen en condiciones arquitectónicas producidas con los materiales, las dimensiones y las características propias de la realidad. Esta actividad tendría un carácter experimental y de investigación y posibilitaría el intercambio de experiencias no sólo entre la arquitectura, la pintura y la escultura, sino también con otras artes como la música, a danza y el cine. Por lo tanto, lo que se propone es un partenariado entre diversas disciplinas artísticas, articuladas en un proceso que prevé relaciones variadas marcadas por la permanente vitalidad y por la búsqueda de nuevas posibilidades que resulten en fecundas transformaciones ${ }^{24}$. En este momento Le Corbusier ya no considera la relación entre las artes como síntesis, sino como interlocución

\footnotetext{
${ }^{22}$ Lúcio Costa. El Arquitecto y la Sociedad Contemporánea) 1952. In El artista en la sociedad contemporánea. Conferência Internacional de Artistas, Venecia, 22-28 de septiembre de 1952. Londres: UNESCO, julio de 1954, pp.89-100. El texto también está publicado en Lúcio Costa. Registro de uma vivência. São Paulo: Empresa das Artes, 1995, p.268-275.

${ }^{23}$ El texto de la intervención verbal de Lúcio Costa en el Congreso de Venecia de 1952 está publicado en la revista BrasilArquitetura Contemporânea n.1. Rio de Janeiro, ago-set 1953, pp.2,3. Y también en el libro: Lucio Costa. Registro de uma vivência. São Paulo, Empresa das Artes, 1995, pp.266-267 con el título Arte, manifestación normal de la vida. En este libro Lúcio Costa esclarece que cuando viajaba de Francia a Venecia, para participar del Congreso de la UNESCO, encontró en el tren a Le Corbusier que también viajaba a Venecia y que este le dio a ler el texto que presentaría en el congreso.

${ }^{24}$ Le Corbusier Les rapports des artistas entre eux: Synthèse des arts plastiques,. In Cäsar Menz org. Le Corbusier ou la Synthèse des arts. Genève: Skira, 2006, p.259-260.(communication faite a la Conférence internationale des artistas. Venise: Unesco, 1952. (FLC U3-7, 317 a 321). Publicación brasileña con el título: Canteiro de Síntese das Artes Maiores. Comunicación de Le Corbusier en la Conferencia Internacional de Artistas. Venecia, 25 de setiembre de 1952.In Cecília Rodrigues dos Santos et al. Le Corbuisier e o Brasil. São Paulo, Tessela / Projeto Editora, 1987, p.239-241. (FLC$\mathrm{U} 3,10.449 / 450)$
} 
productiva que mantiene las especificidades de cada una de ellas y en este sentido se acerca a la reflexión conducida por Lúcio Costa en el mismo seminario.

Las nuevas concepciones de Le Corbusier sobre la relación entre arte y arquitectura encuentran un espacio favorable para nuevas especulaciones arquitectónicas en su proyecto de pabellón para la Exposición de Bruselas, en 1958. La construcción provisoria representada por los pabellones siempre se mostró campo privilegiado de experimentación arquitectónica y Le Corbuisier no rehúye al desafío. En este caso la obra es concebida por solicitud de la empresa holandesa Philips, que desea un espacio para presentar no sólo sus productos sino fundamentalmente los resultados de sonido y luz posibilitados por la alta tecnología empleada en su producción. La respuesta de Le Corbuisier a esta demanda es la concepción de una envoltura arquitectural destinada a albergar un poema electrónico, obra que sintetizaría todas las potencialidades de las nuevas tecnologías. Para la concreción de la propuesta, será necesario movilizar varios frentes de acción, como la ingeniería, la arquitectura, la música y las artes visuales.

La arquitectura del Pabellón Philips es de superficies curvas que construyen su espacialidad. El cálculo de esas elaboradas superficies fue realizado por el ingeniero de origen griego Iannis Xenakis, que en la ocasión trabajaba en el estudio de Le Corbusier. Con gran interés por la música y por la matemática, Xenakis encuentra en la convivencia con Le Corbusier la posibilidad de construir especulaciones formales alimentadas por los estudios de geometría y composición conducidos por el arquitecto. Su intención era alcanzar la sensibilidad del espectador con efectos de sonido y luz y así evocar la tecnología que los hacía posibles. Para viabilizar sus objetivos, aprovecha la variación de curvas y rectas que define los partes de la superficie del pabellón para regular la variación de densidades sonoras. La movilidad de los cóncavos y convexos relativiza las relaciones topológicas de posición y dialoga con las imágenes y la música que componen el poema electrónico, concebido partiendo de una investigación de Le Corbuisier.

El poema electrónico duraba diez minutos y las paredes del pabellón funcionaban como pantallas de proyecciones que componían una narrativa de música e imágenes. El músico contemporáneo Edgar Varèse fue escogido para componer la melodía que daría ritmo a las imágenes seleccionadas por Le Corbuisier. La escultura O Dia (El día) de Michelangelo inauguraba la serie de imágenes y la seguían imágenes de campos de concentración, de la Anunciación de Giotto, de divinidades negras, de un telescopio, de la cabeza de un toro, de la torre Eiffel, de una galaxia. El poema concluía con el dibujo de una mano abierta, recurrente en el imaginario de Le Corbusier, que en ese momento aparece como símbolo de paz y conciliación, sintetizando la restablecimiento de la cultura europea de posguerra. ${ }^{25}$.

La mano que cierra el poema electrónico se materializa en el proyecto de Le Corbusier para Chandigarh, en India. De hecho, la búsqueda de la variedad de imágenes que componía el poema hecho de luz y sonidos fue conducida por Le Corbusier a la India. En ellas acaece la confrontación de Le Corbusier con otra cultura, que alimentará su imaginario con símbolos y objetos que comparecen en los paneles de colores y densos que pueblan las construcciones propuestas para el centro cívico de la nueva ciudad.

Para Le Corbusier, la síntesis de las artes es una proposición que se modifica a lo largo del tiempo, un mote que promueve la reflexión de la arquitectura en tanto fenómeno poético, señalando su dimensión estética en

\footnotetext{
${ }^{25}$ Las informaciones sobre el Pabellón Philips se basan en el libro de Alessandra Capanna Le Corbuisier Padiglione Philips. Torino: Testo \& Immagine, 2000, que contiene una cuidadosa investigación y documentación sobre esta obra;.y también: Peter Bienz. Il Poème électronique di Le Corbusier e il padiglione Philips all'Esposizione mondiale di Bruxelles del 1958. In Domus 828. Milano: Ed. Domus, luglio-agosto, 2000, pp.16-23.
} 
constante diálogo con el racionalismo de la máquina. A través de ese principio, el arquitecto busca reunir las artes en torno de una misma investigación, volcada a la renovación de la elaboración plástica, en la que colores y formas interactúan en un acuerdo espacial, como manifestación de una nueva época. Mediante las varias inflexiones tomadas por el tema de la síntesis de las artes es posible aprender las contradicciones y las dificultades del proyecto moderno, que no se detiene en la pura racionalidad y en el funcionalismo a que muchas veces se lo reduce y, de esta manera, logra revelar su complejidad interna.

\section{Procedencia de las imágenes}

1. Revista do IPHAN, n.19. Arquivo do IPHAN, Rio de Janeiro

2. Revista do IPHAN, n.19. Arquivo do IPHAN, Rio de Janeiro.

3. Ministério da Educação e Saúde. Rio de Janeiro. Foto da autora.

4. Ministério da Educação e Saúde, Rio de Janeiro. Foto da autora.

5. Ministério da Educação e Saúde, Rio de Janeiro. Foto da autora.

6. Igreja da Pampulha, Belo Horizonte. Foto da autora.

\section{Bibliografía/referencias}

Almeida, Paulo Mendes de. De Anita ao Museu. São Paulo: Editora Perspectiva, 1975.

Anales del Congreso organizado por la UNESCO: El artista en la sociedad contemporánea. Conferência Internacional de Artistas, Venecia, 22-28 de septiembre de 1952. Londres: UNESCO, julio de 1954.

Bienz, Peter. Il Poème électronique di Le Corbusier e il padiglione Philips all'Esposizione mondiale di Bruxelles del 1958. En Domus 828. Milano: Ed. Domus, luglio-agosto, 2000, pp.16-23.

Calatrava, Juan. Un autre Le Corbusier: l'idée de la synthèse des arts majeurs. En La lettre du Collège de France. Paris: Collège de France, abril 2010, no. 28, pp.18-28. Consultado na versão gravada hospedada na internet em: http://lettre-cdf.revues.org/1049.

Capanna, Alessandra. Le Corbusier Padiglione Philips. Torino: Testo \& Immagine, 2000.

Cohen, Jean-Louis. Le Corbusier. La planète comme chantier. Paris: Les Éditions Textuel, 2005.

Comas, Carlos Eduardo. Protótipo e Monumento, um ministério, o ministério. En Textos Fundamentais sobre história da arquitetura moderna: vol.II, organización Abílio Guerra. São Paulo: Romano Guerra, 2010, p.63-77.

Costa, Lúcio. Razões da Nova Arquitetura (1934). En Lúcio Costa. Registro de uma Vivência. São Paulo: Empresa das Artes, 1995, p.108-16.

El Arquitecto y la Sociedad Contemporánea, (1952). En El artista en la sociedad contemporánea. Conferência Internacional de Artistas, Venecia, 22-28 de septiembre de 1952. Londres: UNESCO, julio de 1954, pp.89-100.

Gabetti, Roberto; Olmo, Carlo. Le Corbuisier e L'Esprit Nouveau. Torino: Einaudi Editori, 1975.

Galvão, Anna Beatriz Ayroza. A monumentalidade em Lúcio Costa: projeto de arquitetura e cidade moderna. Tesis de doctorado. São Paulo: FAUUSP, 2005.

Giedion, Sigfried O Brasil e a Arquitetura Contemporânea (Zuric, 1956). En Henrique E. Mindlin Arquitetura Moderna no Brasil. Rio de Janeiro: Aeroplano, 1999. (prefácio)

In Search of a New Monumentality. En Architectural Review, n.621, setiembre, 1948, p.117-128,

Le Corbusier. "A Arquitetura e as Belas-Artes ( L'Architecture et les Arts Majeurs) (1936). En Revista do Patrimônio Histórico e Artístico Nacional n.19. Rio de Janeiro, 1984, p.53-68. 
Le tendenze dell'architettura razionalista in rapporto alla collaborazione della pittura e della scultura (1936). En Le Corbuisier Scritti, org. Rosa Tamburini. Torino: Einaudi Editori, 2003, pp.281-294.

L'Espace Indicible. En L'Architecture d'aujour'hui, (número fora de série). Paris: Éditions de L'Architecture d'aujour'hui, 1946, pp.9-10.

Canteiro de Síntese das Artes Maiores (1952). En Cecília Rodrigues dos Santos et al. Le Corbuisier e o Brasil. São Paulo: Tessela / Projeto Editora, 1987, p.239-241. (FLC- U3.10. 449/450)

Les rapports des artistas entre eux: Synthèse des arts plastiques,.In Cäsar Menz org. Le Corbusier ou la Synthèse des arts. Genève: Skira, 2006, p.259-260.(communication faite a la Conférence internationale des artistas. Venise: Unesco, 1952) FLC U3-7, 317 a 321).

Moos, Stanislaus von. Exhibition Architect? Otra mirada sobre la "síntesis" de Le Corbusier. En Juan Calatrava org. Doblando el Ángulo Recto. Siete ensayos em torno a Le Corbusier. Madrid: Circulo de Bellas Artes, 2009, pp.61-62.

Ockman, Joan. A Plastic Epic. The Synthesis of the Arts Discourse in France in the Mid-Twentieth Century. En Eeva-Liisa Pelkonen and Esa Laaksonen, (eds) Architecture + art. New Visions, New Strategies. Helsinki: Alvar Aalto Academy, 2007, pp. 30-61.

Ozenfant e Jeanneret (Le Corbusier). Depois do cubismo. Introdução Carlos Alberto Ferreira Martins. São Paulo: Cosac Naify, 2005. 